\title{
AVALIAÇÃO VESTIBULAR NO TREMOR ESSENCIAL
}

\author{
Vestibular evaluation in the essential tremor
}

Bianca Simone Zeigelboim ${ }^{(1)}$, Cláudia Mittelmann ${ }^{(2)}$

\section{RESUMO}

Tema: o tremor essencial é familial em cerca de $50 \%$ dos casos, com uma herança autossômica, possui início insidioso e é lentamente progressivo. Procedimentos: avaliou-se no Setor de Otoneurologia de um Hospital Particular em fevereiro de 2007, uma paciente do sexo feminino, branca, 59 anos, casada, artista plástica, com história de tremor na cabeça desde os dois anos de idade (sic). A paciente relata queixa de tontura há vários meses de origem súbita sem acompanhamento de náusea e/ou queda. Nega perda de força muscular e formigamento em membros superiores e inferiores, rebaixamento da acuidade auditiva e zumbido. A paciente relata que um de seus filhos possuiu tremor nas mãos há dois anos e avós maternos e paternos com Parkinson. Realizaram-se os seguintes procedimentos: anamnese, inspeção otológica e avaliação vestibular por meio da vectoeletronistagmografia. Resultados: observaram-se os seguintes achados ao exame vestibular: nistagmo de posicionamento com características centrais, nistagmo espontâneo presente com os olhos abertos, nistagmo semi-espontâneo do tipo múltiplo e hiper-reflexia em valor absoluto à prova calórica $20^{\circ} \mathrm{C}(\mathrm{OD}$ e OE). Conclusão: o exame vestibular mostrou-se sensível e importante para captar alterações em provas que sugerissem envolvimento do sistema nervoso central.

DESCRITORES: Tremor Essencial; Vertigem; Nistagmo Fisiológico; Testes de Função Vestibular

\section{INTRODUÇÃO}

O tremor é definido como um movimento involuntário, oscilatório, rítmico, de uma ou várias partes do corpo, decorrente de contrações síncronas ou alternantes de músculos antagonistas. Dentre os vários tipos de tremor, o essencial é o de maior prevalência. Por muitos anos, utilizou-se o termo "benigno" para caracterizar esse tipo de tremor. Atualmente, essa denominação não é mais aplicada, pois minimiza o impacto da incapacidade gerada pelo tremor em um grande número de pacientes ${ }^{1}$.

O tremor essencial (TE) pode ocorrer em qualquer idade, mas, estudos epidemiológicos variam amplamente, dependendo da população estudada. Sua distribuição étnica e geográfica é universal, afetando de 0,08 a 220 indivíduos por 1000 habitantes, sendo sua taxa de prevalência de até $5 \%$ em

(1) Fonoaudióloga; Coordenadora do Programa de Mestrado e Doutorado em Distúrbios da Comunicação da Universidade Tuiuti do Paraná; Doutora em Ciências dos Distúrbios da Comunicação Humana pela Universidade Federal de São Paulo.

(2) Fonoaudióloga do Hospital Iguaçu; Especialista em Audiologia Clínica pelo CEFAC - Saúde e Educação. uma população após os 40 anos, e de $20 \%$ em uma população geriátrica, sem predominância de sexo ou raça. $A$ idade de início não prediz o prognóstico clínico nem a resposta terapêutica ${ }^{2,3}$.

O TE é familial em cerca de $50 \%$ dos casos, com uma herança autossômica, possui início insidioso, é lentamente progressivo, há grande variabilidade em seu curso clínico e recentemente, dois genes relacionados foram mapeados nos cromossomos $3 q 13$ e $2 p 22-25^{4-6}$. Muitos fatores podem influenciar a intensidade do tremor: fadiga, extremos de temperatura, fatores emocionais, estimulantes do sistema nervoso central e tabagismo. Mesmo ao longo do dia pode haver variação na intensidade do tremor, desaparecendo durante o sono ${ }^{7}$.

Caracteristicamente, o tremor acomete os membros superiores com movimentos de flexão/extensão dos dedos e das mãos, podendo ou não acometer ambas as mãos ${ }^{7}$.

O tremor cefálico sucede o das mãos, variando de 20 a 50\%. O envolvimento cefálico ocorre tanto na direção horizontal, quanto na vertical, podendo ocorrer flutuações espontâneas entre os dois tipos. De maneira mais rara, o tremor pode ser do tipo pronação/supinação semelhante ao tremor parkinsoniano ${ }^{2,8}$. 
Observam-se, com menos freqüência, contrações rítmicas dos músculos fonatórios, que se manifestam por alterações na entoação e volume dos sons, dificultando sua sustentação, tornando a fala disártrica em casos avançados ${ }^{2,8}$.

Os mecanismos fisiopatológicos envolvidos na gênese do TE ainda não estão bem esclarecidos. Atualmente não foi identificada nenhuma doença ou lesão estrutural no sistema nervoso central relacionada a origem do tremor ${ }^{1}$. A hipótese olivar é a mais aceita para entender melhor os mecanismos fisiopatológicos envolvidos. Estudos demonstram um aumento da utilização de glicose na região olivar, além de aumento de fluxo sanguíneo no cerebelo, núcleo rubro e tálamo ${ }^{9,10}$.

Indivíduos com TE, de acordo com essa hipótese, teriam um aumento de sincronização dos neurônios olivares e uma ritmicidade neuronal. Isto poderia ser resultado de vários fatores: alterações de propriedades da rede neuronal olivar, modificações da neuromodulação dessa mesma rede e aumento da condutância da membrana subjacente às oscilações neuronais. Essas oscilações neuronais poderiam ocorrer isoladamente ou em conjunto. A oscilação olivar alterada é transmitida e possivelmente amplificada através do cerebelo, produzindo recrutamento de áreas do tronco encefálico (núcleo rubro e núcleos reticulares), tálamo e córtex motor ${ }^{11}$.

Segundo a Movement Disorder Society, os critérios para diagnóstico do TE ${ }^{12}$ são:

\section{Critérios de inclusão}

a) Tremor postural bilateral e simétrico ou tremor cinético envolvendo mãos e antebraços, visível e persistente.

b) Tremor adicional ou isolado da cabeça, na ausência de postura anormal da região cervical.

\section{Critérios de exclusão}

a) Outros sinais neurológicos anormais, especialmente distonia.

b) Presença de causas conhecidas de tremor fisiológico exacerbado, incluindo exposição a medicamentos tremorigênicos ou abstinência a drogas.

c) História ou evidência clínica de tremor psicogênico.

d) Evidência convincente de início súbito ou deterioração em surtos do tremor.

e) Tremor ortostático primário.

f) Tremor tarefa-específico ou posição-específico, incluindo tremores ocupacionais e tremor primário da escrita.

g) Tremor isolado da língua ou mandíbula.

h) Tremor isolado dos membros inferiores.
As opções de tratamento disponíveis para o TE são: medidas físicas e psicológicas, mudança de hábitos de vida, abordagem farmacológica, quimiodenervação com toxina botulínica e cirúrgico ${ }^{1}$.

Os medicamentos tradicionalmente indicados são o propranolol ${ }^{13} \mathrm{e}$ a primidona. $\mathrm{O}$ uso dos betabloqueadores é a principal arma terapêutica ${ }^{14}$.

A avaliação otoneurológica é um conjunto de procedimentos que permite a exploração semiológica dos sistemas auditivo e vestibular e de suas relações com o sistema nervoso central ${ }^{15}$.

A vestibulometria é um método de avaliação não invasivo cujos objetivos são: a) ajudar na confirmação do comprometimento vestibular; b) reconhecer o lado lesado; c) localizar a lesão (periférica, central ou mista); d) verificar o tipo da lesão vestibular (irritativa ou deficitária); e) caracterizar a intensidade da lesão (leve, moderada ou severa) e f) monitorar a evolução do paciente vertiginoso ${ }^{15}$.

O objetivo do presente estudo foi apresentar os achados vestibulares em um caso com diagnóstico de TE e ressaltar a importância e a sensibilidade da VENG em captar alterações que sugiram envolvimento do sistema nervoso central.

\section{APRESENTAÇÃO DO CASO}

Avaliou-se uma paciente do sexo feminino com diagnóstico de TE, de 59 anos de idade, encaminhada ao Setor de Otoneurologia de um Hospital Particular na cidade de Curitiba-PR.

Realizaram-se os seguintes procedimentos:

\section{Anamnese}

Aplicou-se um questionário com ênfase aos sinais e sintomas otoneurológicos, antecedentes pessoais e familiares.

\section{Avaliação Otorrinolaringológica}

Realizada pelo médico do hospital Iguaçu com o objetivo de excluir qualquer alteração que pudesse interferir no exame.

\section{Avaliação Vestibular}

A paciente foi submetida às seguintes provas que compõem o exame vestibular:

\section{Sem registro}

- Pesquisou-se o nistagmo e a vertigem de posição/posicionamento através da manobra de Brandt e Daroff ${ }^{16}$.

- Pesquisaram-se os nistagmos espontâneo e semi-espontâneo com os olhos abertos, no olhar frontal e a $30^{\circ}$ de desvio do olhar para a direita, esquerda, para cima e para baixo. 


\section{Com registro}

Para a realização da vectoeletronistagmografia (VENG) utilizou-se um aparelho termossensível, com três canais de registro, da marca Berger, modelo VN316. Após a limpeza da pele das regiões periorbitárias com álcool, colocaram-se, fixados com pasta eletrolítica, um eletródio ativo no ângulo lateral de cada olho e na linha média frontal, formando um triângulo isósceles, que permitiu a identificação dos movimentos oculares horizontais, verticais e oblíquos. Este tipo de VENG possibilitou obter medidas mais precisas da velocidade da componente lenta (correção vestibular) do nistagmo.

Utilizou-se uma cadeira rotatória pendular decrescente da marca Ferrante, um estimulador visual marca Neurograff, modelo EV VEC, e um otocalorímetro a ar, da marca Neurograff, modelo NGR 05.

Realizaram-se as seguintes provas oculares e labirínticas à VENG, segundo os critérios propostos por diversos autores ${ }^{17,18}$.

- Calibração dos movimentos oculares: nesta etapa do exame, o aspecto clínico avaliado foi a regularidade do traçado, tornando as pesquisas comparáveis entre si.

- Pesquisa dos nistagmos espontâneo (olhos abertos e fechados) e semi-espontâneo (olhos abertos): neste registro avaliaram-se a ocorrência, direção, efeito inibidor da fixação ocular (EIFO) e o valor da velocidade angular da componente lenta (VACL) máxima do nistagmo.

- Pesquisa do rastreio pendular para a avaliação da ocorrência e do tipo de curva.

- Pesquisa do nistagmo optocinético, à velocidade de $60^{\circ}$ por segundo, nos sentidos anti-horário $(\mathrm{AH})$ e horário $(\mathrm{H})$, na direção horizontal. Avaliaram-se a ocorrência, direção, VACL máxima às movimentações anti-horária e horária do nistagmo.

- Pesquisa dos nistagmos pré e pós-rotatórios à prova rotatória pendular decrescente, com estimulação dos ductos semicirculares laterais, anteriores e posteriores. Para a estimulação dos ductos semicirculares laterais (horizontais) a cabeça foi fletida $30^{\circ}$ para frente. $\mathrm{Na}$ etapa seguinte, para a sensibilização dos ductos semicirculares anteriores e posteriores (verticais) o posicionamento da cabeça foi de $60^{\circ}$ para trás e $45^{\circ}$ à direita e, a seguir, $60^{\circ}$ para trás e $45^{\circ}$ à esquerda, respectivamente. Observaram-se a ocorrência, direção, freqüência às rotações antihorária e horária do nistagmo.

- Pesquisa dos nistagmos pré e pós-calóricos realizada com o paciente posicionado de forma que a cabeça e o tronco estivessem inclinados $60^{\circ}$ para trás, para estimulação adequada dos duc- tos semicirculares laterais. $\mathrm{O}$ tempo de irrigação de cada orelha com ar a $42^{\circ} \mathrm{C}, 20^{\circ} \mathrm{C}$ e $10^{\circ} \mathrm{C}$ durou 80s para cada temperatura e as respostas foram registradas com os olhos fechados e, a seguir, com os olhos abertos para a observação do EIFO. Nesta avaliação verificaram-se a direção, os valores absolutos da VACL e o cálculo das relações da preponderância direcional e predomínio labiríntico do nistagmo pós-calórico.

A pesquisa foi realizada após autorização da paciente por meio de assinatura do Termo de Consentimento Livre e Esclarecido.

\section{RESULTADOS}

\section{Anamnese}

Paciente do sexo feminino, branca, 59 anos, casada, artista plástica, com história de tremor na cabeça desde os dois anos de idade (sic). A paciente relata queixa de tontura há vários meses de origem súbita sem acompanhamento de náusea e/ou queda. Nega perda de força muscular e formigamento em membros superiores e inferiores, rebaixamento da acuidade auditiva e zumbido. A paciente relata que um de seus filhos possuiu tremor nas mãos há dois anos e avós maternos e paternos com Parkinson.

\section{Exame Vestibular}

- Nistagmo de posição e/ou posicionamento: presente, do tipo horizontal à esquerda, sem latência, paroxismo e fatigabilidade nas posições decúbito lateral direito e esquerdo;

- Calibração dos movimentos oculares: regular;

- Nistagmo espontâneo: olhos abertos: presente do tipo horizontal à esquerda; olhos fechados: ausente;

- Nistagmo semi-espontâneo: presente do tipo múltiplo;

- Rastreio pendular: Tipo II;

- Nistagmo optocinético: simétrico com VACL AH= 8\% $\%$; VACL H $=10 \%$ s;

- Nistagmo per-rotatório: estimulação dos ductos semicirculares laterais: simétricos com freqüência nistágmica: $\mathrm{AH}=14 ; \mathrm{H}=12 ; \mathrm{PDN}=8 \%$ à esquerda. Estimulação dos ductos semicirculares posteriores: simétricos com freqüência nistágmica: $\mathrm{AH}=35 ; \mathrm{H}=38 ; \mathrm{PDN}=4 \%$ à direita. Estimulação dos ductos semicirculares anteriores: simétricos com freqüência nistágmica: $\mathrm{AH}=37$; $\mathrm{H}=37 ; \mathrm{PDN}=0 \%$.

- Nistagmo pós-calórico: prova calórica realizada com ar; $42^{\circ} \mathrm{C}$ orelha direita: $\mathrm{VACL}=16 \% \mathrm{~s} ; 42^{\circ} \mathrm{C}$ orelha esquerda: $\mathrm{VACL}=6 \% \mathrm{~s} ; 20^{\circ} \mathrm{C}$ orelha direita: $\mathrm{VACL}=26 \%$ 
$\mathrm{VACL}=22 \%$. Presença de EIFO nas quatro estimulações.

- Achados no exame: nistagmo de posicionamento com características centrais, nistagmo espontâneo presente com os olhos abertos, nistagmo semi-espontâneo do tipo múltiplo e hiperreflexia em valor absoluto á prova calórica $20^{\circ} \mathrm{C}$ (OD e OE), Conclusão do exame: Sugestivo de Síndrome Vestibular Central Irritativa Bilateral.

\section{DISCUSSÃO}

O equilíbrio corporal depende da integridade do sistema vestibular: labirinto, nervo vestibulococlear, núcleos, vias e inter-relações no sistema nervoso central, do sistema somatossensorial e da visão ${ }^{15}$. Tonturas e/ou desequilíbrio surgem quando algo interfere no funcionamento normal do sistema de equilíbrio corporal.

O estudo do nistagmo realizado por meio da VENG tem-se constituído como um recurso preciso no topodiagnóstico de várias doenças. Nas síndromes otoneurológicas centrais, observam-se que os sinais de afecção do sistema vestibular central são predominantes em diversas provas labirínticas, fato que não ocorre nas síndromes periféricas ${ }^{19}$.

No caso relatado, observam-se alguns sinais centrais como: a) presença de nistagmo com carac- terísticas centrais, ou seja, sem latência, paroxismo, fatigabilidade e vertigem na pesquisa do nistagmo posicional /posicionamento por meio da manobra de Brandt e Daroff; b) presença de nistagmo espontâneo com os olhos abertos e ausência com os olhos fechados, o que indica a ausência do efeito inibidor da fixação ocular (EIFO) e c) presença de nistagmo do tipo múltiplo na pesquisa do nistagmo semi-espontâneo, sendo este visível e registrável.

$\mathrm{Na}$ literatura compulsada com relação à parte otoneurológica, encontramos apenas um estudo 20 que avaliou 14 pacientes com TE por meio da eletrooculografia. $\mathrm{O}$ autor encontrou déficits da função vestibular em 8 pacientes, sendo essas alterações extremamente importantes, apresentando-se no movimento de perseguição e supressão patológica da constante de tempo do reflexo vestibuloocular (RVO), sugerindo que este tipo de disfunção ocorre em estágios avançados da doença. O autor refere que esses déficits oculomotores podem indicar um dano no vérmis-caudal.

\section{CONCLUSÃO}

O caso apresentado demonstra que o exame vestibular mostrou-se sensível e importante para captar alterações em provas que sugerissem envolvimento do sistema nervoso central.

\begin{abstract}
Background: essential tremors are family-related in about $50 \%$ of the cases with an autosomal inheritance and they register an insidious beginning with a slow progression. Procedure: a 59 year old, white female patient, married and whose occupation is a plastic artist with a history of head tremors since she was two years (sic) old was evaluated in the Otoneurology sector of a private hospital, during the period from February 2007. The patient had been complaining of dizziness from unknown origin for several months without accompanying nausea and/or falls. She denied any loss of muscular strength or tingling in her upper and lower members and neither any lowering of her auditory sharpness nor buzzing. The patient informed that one of her children suffered hand tremors two years ago and also that both grandparents had Parkinson's disease. The following procedures were performed: anamnesis, otological inspection and vestibular evaluation through vectoelectronystagmography. Results: the following findings from the vestibular exam were observed: positioning nystagmus with central characteristics, spontaneous nystagmus with the eyes open, semi-spontaneous nystagmus of the multiple and hyperreflexia type in readings absolute to the caloric test at $20^{\circ} \mathrm{C}$ (RE and LE). Conclusion: the vestibular exam was shown to be sensitive and important for garnering alterations in tests that suggested involvement of the central nervous system.
\end{abstract}

KEYWORDS: Essential tremor; Vertigo; Nystagmus, Physiologic; Vestibular Function Tests 


\section{REFERÊNCIAS}

1. Gonçalves MRR, Barbosa ER, Scaff M. Diagnóstico e tratamento do tremor essencial. Diag Tratamento. 2003; 8(1):9-16.

2. Larsson T, Sjögren T. Essential tremor: a clinical and genetic population study. Acta Psychiatr Neurol Scand. 1960; 36(144):1-176.

3. Louis ED, Ottman R, Hauser A. How common is the most common adult movement disorder? Estimates of the prevalence of essential tremor throughout the world. Mov Disord. 1998; 13:5-10.

4. Gulcher JR, Jónsson $O$, Kong A, Kristjánsson K, Frigge ML, Kárason A, et al. Mapping of a familial essential tremor gene, FET1, to chromosome 3q13. Nat Genet. 1997; 17(1):84-7.

5. Higgins JJ, Loveless JM, Jankovic J, Patel PI. Evidence that a gene for essential tremor maps to chromosome $2 p$ in four families. Mov Disord. 1998; 13(6):972-7.

6. Aridon $P$, Ragonese $P$, De Fusco $M$, Salemi G, Casari G, Savettieri G. Further evidence of genetic heterogeneity in familial essential tremor. Parkinsonism Relat Disord. 2007; 14(1):15-8.

7. Hubble JP, Busenbark KL, Koller WC. Essential tremor. Clin Neuropharmacol. 1989; 12(6):453-82.

8. Koller WC, Busenbark KL, Miner K. The relationship of essential tremor to other movement disorders: report on 678 patients. Ann Neurol. 1994; 35(6):717-23.

9. Hallett M, Dubinsky RM. Glucose metabolism in the brain of patients with essential tremor. J Neurol Sci. 1993; 114(1):45-8.

10. Jenkins IH, Bain PG, Colebatch JG, Thompson $\mathrm{PD}$, Findley LJ, Frackowiak RS, et al. Apositron emission tomography study of essential tremor: evidence for overactivity of cerebellar connections. Ann Neurol. 1993; 34(1):82-90.

11. Sugihara I, Lang EJ, Llinás R. Serotonin modulation of inferior olivary oscillations and synchronicity: a multiple-electrode study in the rat cerebellum. Eur J Neurosci. 1995 apr; 7(4):521-34.

12. Deuschl G, Bain P, Brin M. Consensus statement of the movement disorder society on tremor. Ad Hoc Svientific Commitee. Mov. Disord. 1998; 13(S3):2-23.

13. Troiano AR, Teive HAG, Fabiani GB, Zavala JAA, Sá DS, Germiniani FMB et al. Uso do propranolol de ação prolongada em 40 pacientes com tremor essencial e virgens de tratamento: um ensaio clínico não controlado. Arq Neuropsiquiatr. 2004: 62(1):86-90.

14. Koller WC, Hristova A, Brin M. Pharmacologic treatment of essential tremor. Neurol. 2000; 54(4): S30-8.

15. Ganança MM, Caovilla HH, Munhoz MSL, Silva MLG, Frazza MM. As etapas da equilibriometria. In: Caovilla HH, Ganança MM, Munhoz MSL, Silva MLG. Equilibriometria clínica. 1.ed. São Paulo: Atheneu; 1999. p.41-79.

16. Brandt T, Daroff RB. Physical therapy for benign paroxysmal positional vertigo. Arch Otolaryngol. 1980; 106:484-5.

17. Padovan I, Pansini M. New possibilities of analysis in electronystagmography. Acta Otolaryngol. 1972; 73(2):121-5.

18. Mangabeira-Albernaz PL, Ganança MM, Pontes PAL. Modelo operacional do aparelho vestibular. In: Mangabeira-Albernaz PL, Ganança MM. Vertigem. 2.ed. São Paulo: Moderna; 1976. p. 29-36.

19. Mangabeira-Albernaz PL, Ganança MM. Vertigem. 2.ed. São Paulo: Moderna; 1976. p.1-174.

20. Helmchen C, Hagenow A, Miesner J, Sprenger A, Rambold $\mathrm{H}$, Wenzelburger $\mathrm{R}$, et al. Eye movement abnormalities in essential tremor may indicate cerebellar dysfunction. Brain. 2003; 126(6):1319-32.

RECEBIDO EM: 14/05/2007

ACEITO EM: 22/04/2008

Endereço para correspondência:

Rua Gutemberg, 99

Curitiba - PR

CEP: $80420-030$

Tel: (41) 3331-7807 / (41) 9198-2888

E-mail: bianca.zeigelboim @utp.br 